\title{
СПОСОБ РАСПРЕДЕЛЕНИЯ ВИДОВ ЛУГОВОЙ ТРАВЫ ПО МАССЕ СВЕЖЕСРЕЗАННОЙ ПРОБЫ
}

Мазуркин П.М., Михайлова С.И.

ФГБОУ ВПО «Поволжский государственный технологический университет», 424000, г. Йошкар-Ола, Россия, e-mail: kaf_po@mail.ru

Оценку видового состава травяного покрова осуществляют статистическим моделированием путем идентификации математических моделей изменения массы срезанной травы на участке и на отдельной пробной площадке в зависимости от ранга видов травяных и травянистых растений. Такая технология позволит повысить точность учета наличия видов травяных и травянистых растений при одновременном упрощении процесса оценки видового состава.

Ключевые слова: трава, виды, пробы, масса, распределения, закономерности

Изобретение [1] относится к измерению показателей качества различных видовых комплексов травяных и травянистых растений, включая и лекарственные виды, на свежесрезанных пробах, преимущественно на пойменных прирусловых лугах, и может быть использовано в экологическом мониторинге территорий с травяным покровом.

Сущность заключается в том, что рельеф исключается и на первое место выступает распределение массы свежесрезанной травы. Однако необходима новая шкала распределения, которая создается из суммы всех масс сырых проб, срезанных с одинаковых по размерам пробных площадок. Сущность также и в том, что срезаются порции травы на площадке по видам растений, и они раскладываются по отдельности. Кучки травы сразу взвешиваются на переносных весах. После взвешивания всех кучек трава выбрасывается. Далее процедура повторяется на следующей пробной площадке.

Ранг устанавливается один раз по иерархии массы всей пробы (табл. 1).

Таблица 1 - Масса свежесрезанной травы по пробным площадкам в 2011 г.

\begin{tabular}{|c|c|c|c|c|c|c|c|c|c|c|c|c|c|c|c|c|c|c|c|c|}
\hline & $\mathrm{Pa}$ & & & & & & & & & & LV 11 & $\mathrm{H}$ & D & 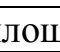 & цадо & К 0,5 & j> & & $\mathrm{M}, \Gamma$ & \\
\hline$\Pi / \Pi$ & $R$ & 1 & 2 & 3 & 4 & 5 & 6 & 7 & 8 & 9 & 10 & 11 & 12 & 13 & 14 & 15 & 16 & 17 & 18 & \\
\hline 1 & 27 & 23 & 14 & 0 & 13 & 33 & 23 & 0 & 0 & 0 & 40 & 13 & 24 & 0 & 0 & 32 & 53 & 18 & 21 & \begin{tabular}{|l|}
307 \\
\end{tabular} \\
\hline 2 & 28 & 27 & 12 & 0 & 15 & 26 & 22 & 0 & 46 & 40 & 0 & 0 & 0 & 26 & 25 & 25 & 0 & 21 & 24 & 309 \\
\hline 3 & 26 & 13 & 0 & 0 & 0 & 30 & 15 & 15 & U & 8 & U & 0 & 0 & 38 & 41 & 0 & 68 & 0 & 22 & 280 \\
\hline 4 & 29 & 39 & 0 & 97 & 17 & 25 & 18 & 0 & 43 & 0 & 49 & 0 & 0 & 40 & 0 & 26 & 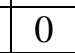 & 14 & 0 & 68 \\
\hline 5 & 25 & 0 & 0 & 0 & 0 & 27 & 15 & 26 & 33 & 0 & 12 & 27 & 10 & 34 & 15 & 15 & 0 & 23 & 0 & 237 \\
\hline 6 & 8 & 0 & 0 & C & 0 & 0 & 16 & 0 & 0 & 0 & 0 & 0 & 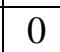 & $\Omega$ & 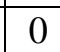 & 0 & 0 & 0 & 26 & 26 \\
\hline 7 & 21 & 0 & 16 & 0 & 0 & 0 & 11 & 19 & 0 & 0 & 25 & 0 & 15 & 0 & 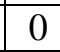 & 0 & 0 & 0 & 29 & 115 \\
\hline 8 & 19 & 0 & 0 & 0 & 0 & 0 & 13 & 27 & 0 & 36 & 20 & 0 & 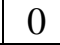 & 0 & 0 & 0 & 0 & 0 & 0 & 96 \\
\hline 9 & 22 & 26 & 0 & 0 & 10 & 0 & 12 & 11 & 0 & 45 & 0 & 0 & 0 & 0 & 27 & 17 & 0 & 0 & 0 & \begin{tabular}{|l|l|}
148 \\
\end{tabular} \\
\hline 10 & 30 & 21 & 28 & 0 & 12 & 29 & 0 & 38 & 48 & 34 & 28 & 10 & 31 & 53 & 0 & 44 & 0 & 15 & 25 & 416 \\
\hline 11 & 16 & 31 & 0 & 0 & 11 & 0 & 10 & 0 & 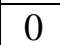 & 0 & 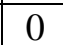 & 9 & 0 & 0 & 0 & 0 & 0 & 0 & 0 & 61 \\
\hline 12 & 13 & 0 & 0 & 0 & 19 & ( & 0 & 0 & 0 & 0 & & 0 & & 0 & 25 & 0 & 0 & 0 & 0 & 44 \\
\hline 13 & 15 & 0 & 11 & 0 & 14 & 0 & 0 & 0 & 0 & 0 & 0 & 0 & 0 & 0 & 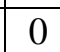 & 21 & 0 & 11 & 0 & 57 \\
\hline 14 & 24 & 20 & 0 & 0 & 19 & 0 & 0 & 23 & U & 0 & 0 & 23 & 0 & 0 & 29 & 29 & 70 & 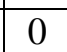 & 0 & 213 \\
\hline 15 & 1 & 0 & 0 & 0 & 10 & 0 & 0 & 0 & 0 & 0 & 0 & 0 & 0 & 0 & 0 & 0 & 0 & 0 & 0 & 10 \\
\hline 16 & 23 & 0 & 0 & 83 & 0 & 0 & 0 & 0 & 0 & 0 & 0 & 14 & 0 & 49 & 0 & 0 & 0 & 8 & 28 & 182 \\
\hline
\end{tabular}




\begin{tabular}{|c|c|c|c|c|c|c|c|c|c|c|c|c|c|c|c|c|c|c|c|c|}
\hline 17 & 17 & 0 & 27 & 0 & 0 & 0 & 0 & 0 & 0 & 0 & 16 & 0 & 27 & 0 & 0 & 0 & 0 & 8 & 0 & 78 \\
\hline 18 & 9 & 0 & 26 & 0 & 0 & 0 & 0 & 0 & 0 & 0 & 0 & 0 & 0 & 0 & 0 & 0 & 0 & 0 & 0 & 26 \\
\hline 19 & 18 & 0 & 15 & 0 & 0 & 0 & 0 & 0 & 30 & 39 & 0 & 0 & 0 & 0 & 0 & 0 & 0 & 0 & 0 & 84 \\
\hline 20 & 5 & 0 & 22 & 0 & 0 & 0 & 0 & 0 & 0 & 0 & 0 & 0 & 0 & 0 & 0 & 0 & 0 & 0 & 0 & 22 \\
\hline 21 & 4 & 0 & 19 & 0 & 0 & 0 & 0 & 0 & 0 & 0 & 0 & 0 & 0 & 0 & 0 & 0 & 0 & 0 & 0 & 19 \\
\hline 22 & 10 & 32 & 0 & 0 & 0 & 0 & 0 & 0 & 0 & 0 & 0 & 0 & 0 & 0 & 0 & 0 & 0 & 0 & 0 & 32 \\
\hline 23 & 2 & 13 & 0 & 0 & 0 & 0 & 0 & 0 & 0 & 0 & 0 & 0 & 0 & 0 & 0 & 0 & 0 & 0 & 0 & 13 \\
\hline 24 & 6 & 0 & 0 & 0 & 0 & 0 & 0 & 0 & 0 & 0 & 0 & 0 & 23 & 0 & 0 & 0 & 0 & 0 & 0 & 23 \\
\hline 25 & 1 & 0 & 0 & 0 & 0 & 0 & 0 & 0 & 0 & 0 & 0 & 0 & 10 & 0 & 0 & 0 & 0 & 0 & 0 & 10 \\
\hline 26 & 20 & 0 & 0 & 0 & 0 & 0 & 0 & 0 & 0 & 0 & 0 & 15 & 0 & 0 & 0 & 18 & 69 & 0 & 0 & 102 \\
\hline 27 & 4 & 0 & 0 & 0 & 0 & 0 & 0 & 0 & 0 & 0 & 0 & 19 & 0 & 0 & 0 & 0 & 0 & 0 & 0 & 19 \\
\hline 28 & 11 & 0 & 0 & 0 & 0 & 0 & 0 & 0 & 0 & 28 & 0 & 0 & 0 & 0 & 0 & 0 & 0 & 12 & 0 & 40 \\
\hline 29 & 3 & 0 & 0 & 0 & 0 & 0 & 0 & 16 & 0 & 0 & 0 & 0 & 0 & 0 & 0 & 0 & 0 & 0 & 0 & 16 \\
\hline 30 & 7 & 0 & 0 & 0 & 0 & 0 & 0 & 0 & 0 & 0 & 0 & 0 & 0 & 0 & 0 & 0 & 0 & 0 & 25 & 25 \\
\hline 31 & 12 & 0 & 0 & 0 & 0 & 0 & 0 & 0 & 0 & 0 & 0 & 0 & 0 & 0 & 28 & 13 & 0 & 0 & 0 & 41 \\
\hline 32 & 14 & 0 & 0 & 0 & 0 & 0 & 0 & 0 & 0 & 0 & 0 & 0 & 0 & 0 & 45 & 0 & 0 & 0 & 0 & 45 \\
\hline
\end{tabular}

Модель рангового распределения $m=f(R)$ (рис. 1) определяется [2,3] параметрами, приведенными в матричной форме в таблице 2 .

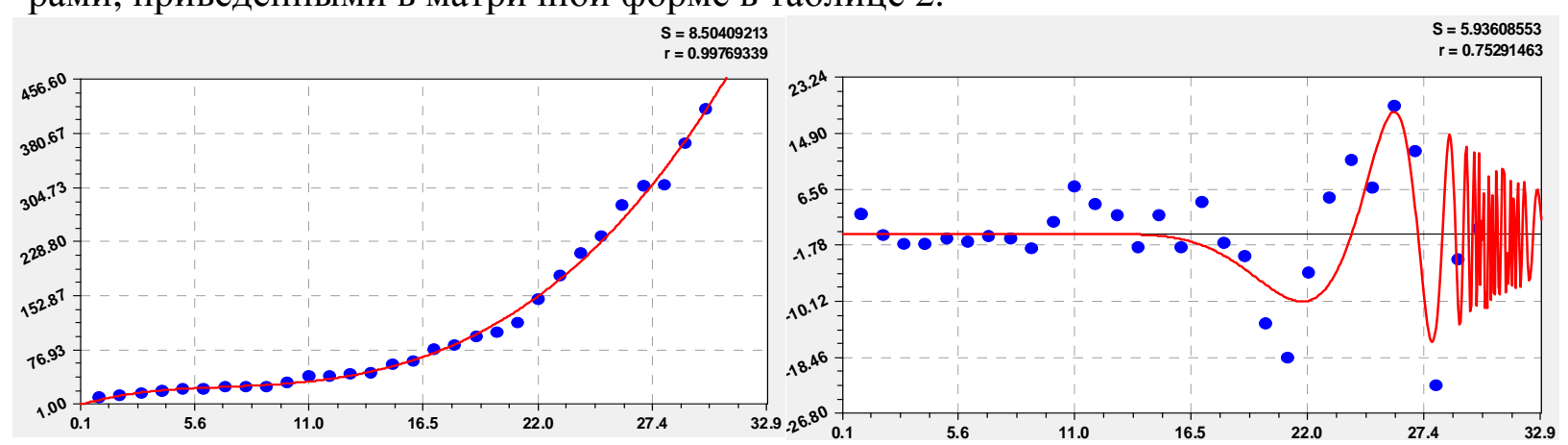

Тренд их первых двух составляющих

Третья (волновая) составляющая

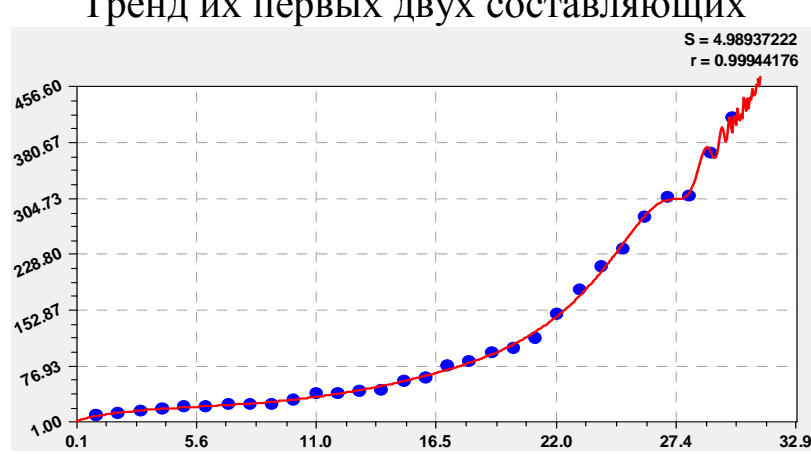

Три составляющие вместе на участке
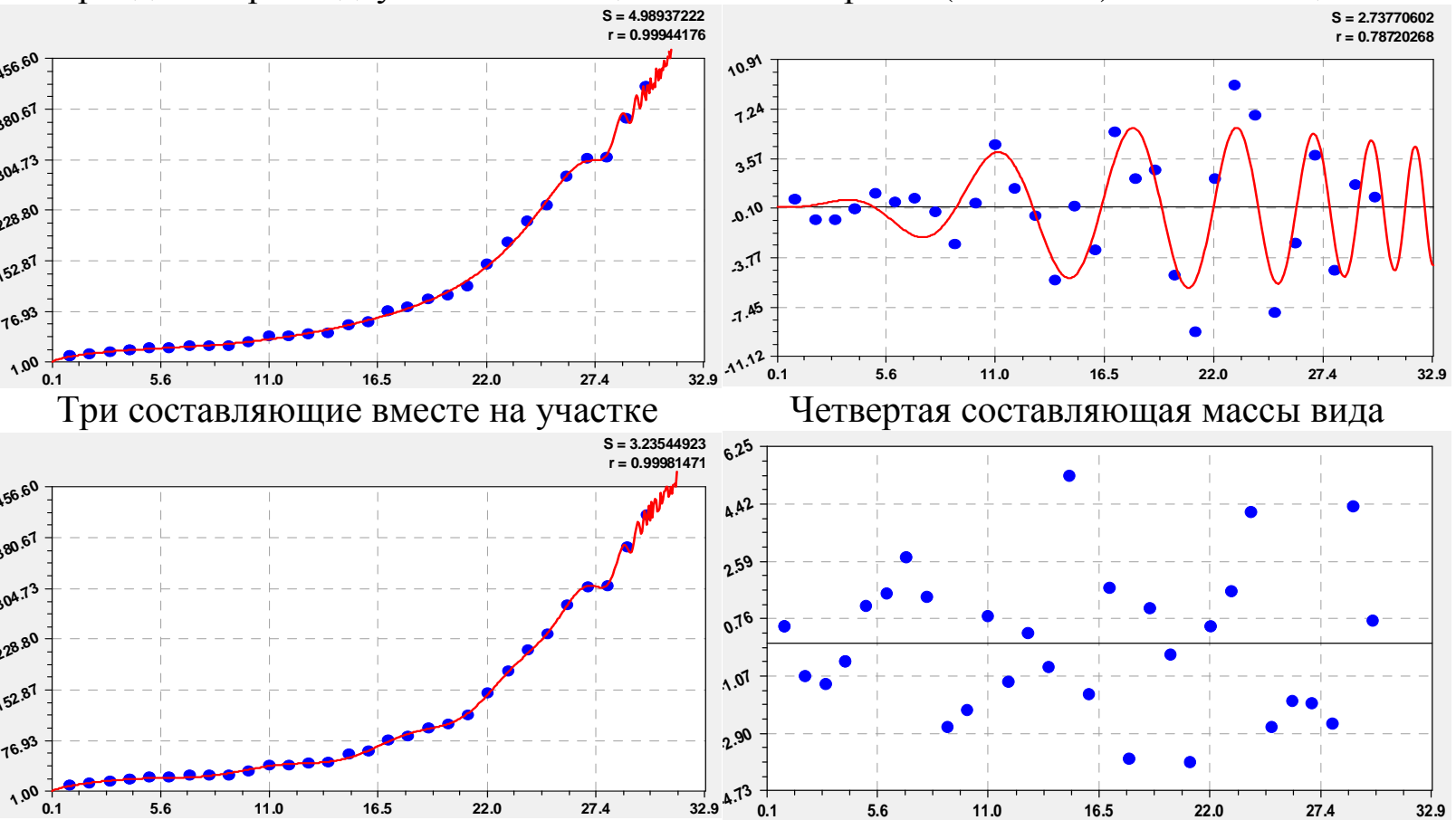

Четыре составляющие вместе

Остатки после четырех составляющих

Рис. 1. Графики модели по первым четырем составляющим изменения массы 
Всего получилось 12 составляющих, из которых 10 стали волновыми функциями. При этом первая и вторая составляющая относятся к тренду, то есть к тенденции изменения массы в зависимости от ранга растения. Первая составляющая показывает показательный рост, что видовое разнообразие по массе может нарастать. Однако, как известно, существует в данных климатических условиях предел продуктивности.

Таблица 2 - Составляющие рангового распределения общей массы видов растений

$$
y_{i}=a_{1 i} x^{a_{2 i}} \exp \left(-a_{3 i} x^{a_{4 i}}\right) \cos \left(\pi x /\left(a_{5 i}+a_{6 i} x^{a_{7 i}}\right)-a_{8 i}\right)
$$

\begin{tabular}{|c|c|c|c|c|c|c|c|c|c|}
\hline \multirow[t]{2}{*}{ № } & \multicolumn{4}{|c|}{ Амплитуда колебания } & \multicolumn{4}{|c|}{ Полупериод и сдвиг колебания } & \multirow{2}{*}{$\begin{array}{l}\text { Коэф. } \\
\text { корр. }\end{array}$} \\
\hline & $a_{1 i}$ & $a_{2 i}$ & $a_{3 i}$ & $a_{4 i}$ & $a_{5 i}$ & $a_{6 i}$ & $a_{7 i}$ & $a_{8 i}$ & \\
\hline 1 & 0,0073115 & 3,20988 & 0 & 0 & 0 & 0 & 0 & 0 & \multirow{4}{*}{0,9998} \\
\hline 2 & 10,38641 & 0,68557 & 0,093271 & 1 & 0 & 0 & 0 & 0 & \\
\hline 3 & $1,17150 \mathrm{e}-18$ & 31,35665 & 9,12664 & 0,56694 & 192,36429 & $-20,46513$ & 0,65354 & $-2,14617$ & \\
\hline 4 & 0,040490 & 2,33539 & 0,078243 & 1,06930 & 4,25834 & $-0,00058236$ & 2,30001 & 2,06444 & \\
\hline 5 & 29,23962 & 0,92691 & 4,53154 & 0,068161 & 2,54349 & $-0,0008$ & 1,90602 & 4,66753 & 0,4858 \\
\hline 6 & 0,000 & 3,51339 & 0,00061378 & 2,37397 & 5,63170 & $-0,0002$ & 2,53257 & 2.59150 & 0,6120 \\
\hline 7 & $-6,36$ & 6.64918 & 21,66972 & 0,20967 & 18,37508 & $-10,01$ & 0,12721 & $-5,77249$ & 0,4910 \\
\hline 8 & $8,51675 \mathrm{e}-5$ & 18,06091 & 1,13055 & 0,96855 & 0,97091 & 0,00040212 & 1,67569 & 2,77602 & 0,9153 \\
\hline 9 & $-3,16084 \mathrm{e} 10$ & 13,94166 & 30,75777 & 0,26113 & 0,58704 & 0,93329 & 0,044086 & $-0,67129$ & 0,8390 \\
\hline 10 & 35,58229 & 0 & 2,02925 & 1 & 2,24102 & $-0,21496$ & 1 & 0,081124 & 0,4751 \\
\hline 11 & 0,0018801 & 1,95030 & 0,63541 & $3,43588 \mathrm{e}-5$ & 0,055196 & 0,013468 & $\begin{array}{l}1,07959 \\
\end{array}$ & $-0,42841$ & 0,9429 \\
\hline 12 & $4,53529 \mathrm{e}-14$ & 20,64068 & 1,84656 & 0,99994 & 16,25830 & 0,68320 & 0,99988 & $-4,19209$ & \\
\hline
\end{tabular}

В таблице 3 приведены данные моделирования по распределению массы видов растений на первой пробной площадке.

Таблица 3 - Составляющие рангового распределения массы видов растений на первой площадке $y_{i}=a_{1 i} x^{a_{2 i}} \exp \left(-a_{3 i} x^{a_{4 i}}\right) \cos \left(\pi x /\left(a_{5 i}+a_{6 i} x^{a_{7 i}}\right)-a_{8 i}\right)$

\begin{tabular}{|c|c|c|c|c|c|c|c|c|c|}
\hline \multirow{2}{*}{$\begin{array}{c}\text { № } \\
i\end{array}$} & \multicolumn{4}{|c|}{ Амплитуда колебания } & \multicolumn{4}{|c|}{ Полупериод и сдвиг колебания } & \multirow{2}{*}{$\begin{array}{l}\text { Коэфф. } \\
\text { коррел. }\end{array}$} \\
\hline & $a_{1 i}$ & $a_{2 i}$ & $a_{3 i}$ & $a_{4 i}$ & $a_{5 i}$ & $a_{6 i}$ & $a_{7 i}$ & $a_{8 i}$ & \\
\hline 1 & $4,06492 \mathrm{e}-5$ & 3.96302 & 0 & 0 & 0 & 0 & 0 & 0 & \multirow{4}{*}{0,9415} \\
\hline 2 & $-1,11518 \mathrm{e}-6$ & 0 & $-14,92198$ & 0,019882 & 30,67158 & $-25,96078$ & 0,015295 & $-1,76402$ & \\
\hline 3 & $3,83986 \mathrm{e}-60$ & 104,7660 & 10,09853 & 0,99945 & 14,49427 & $-0,94531$ & 1,00348 & $-5,39219$ & \\
\hline 4 & $-0,32715$ & 1,16377 & 0 & 0 & 2,36467 & $-0,028562$ & 1 & $-1,58332$ & \\
\hline 5 & $1,51983 \mathrm{e}-104$ & 116,87351 & 2,42612 & 1,26466 & 1,29333 & $-0,0070573$ & 1,06028 & 1,48098 & 0,7498 \\
\hline 6 & 195,08758 & 7,59599 & 4,20310 & 1 & 1 & 0 & 0 & 0 & 0,6168 \\
\hline 7 & 0,77808 & 0,54830 & 0,037546 & 1 & 94,43942 & $-3,42139$ & 1 & 2,04402 & 0,5935 \\
\hline 8 & 0,060578 & 5,32262 & 2,04138 & 0,61484 & 10,88170 & $-0,22885$ & 1,05496 & 1,63635 & 0,7258 \\
\hline 9 & $-0,040826$ & 3,29285 & 0,38943 & 1 & 8,72733 & $-3,79745$ & 0,17770 & $-3,61267$ & 0,5814 \\
\hline 10 & 0,11735 & 0 & $-0,058775$ & 1 & 271,06878 & $-152,70910$ & 0,11875 & $-1,98679$ & 0,1464 \\
\hline 11 & $-0,13108$ & 0 & $-0,084116$ & 1 & 5,02968 & $-0,017724$ & 0,48429 & 1,12411 & 0,6251 \\
\hline 12 & $1,15300 \mathrm{e} 9$ & 10,72950 & 26,07506 & 0,24068 & 0,59919 & 0,074415 & 0,60576 & 1,98021 & 0,6985 \\
\hline 13 & $-0,20616$ & 0,31503 & 0,00092467 & 2,01746 & 10,67463 & $1,73355 \mathrm{e}-5$ & 2,98888 & 0,29246 & 0,5351 \\
\hline 14 & $-3,77320 \mathrm{e}-20$ & 19,82815 & 0,63303 & 1,06122 & 4,33569 & $-0,00078700$ & 2,15198 & \begin{tabular}{|l|}
0,24657 \\
\end{tabular} & 0,8504 \\
\hline 15 & $-0,41366$ & 0 & 0,026636 & 1,50481 & 0,053719 & 0,42096 & 0,64871 & 1,62853 & 0,6660 \\
\hline 16 & $-1,15640 \mathrm{e}-20$ & 24,19586 & 1,38803 & 1,00005 & 4,23890 & $-0,10292$ & 0,99925 & $-3,70678$ & 0,7593 \\
\hline
\end{tabular}

Из данных таблицы 3 заметно, что тренд включает только один показательный закон без стрессового возбуждения всей популяции, так как она стала всего из 10 членов по видам растений. Но зато становится понятным, что нулевые значения массы от- 
сутствующих видов растений имеют под собой физико-биологическую основу: в данных условиях произрастания появляются только те виды, которые успешны, а остальные находятся семенами в режиме ожидания. Тогда, фиксируя рельеф и другие условия произрастания, можно будет изучать адаптационную способность всего видового состава не только к рельефу, но и к ежегодным гидрометеорологическим показателям.

В таблице 4 даны расчетные показатели адекватности моделей по рангам, которые приняты по вектору предпорядка предпочтительности «хуже $\rightarrow$ лучше». Чем больше масса общая по всем пробам на участке, тем лучше для видового состава растений.

Таблица 4 - Относительная погрешность рангового распределения видов травы

\begin{tabular}{|c|c|c|c|c|c|c|c|c|c|}
\hline \multirow{2}{*}{ Наименование травы } & \multirow{2}{*}{$\begin{array}{c}\text { Ранг } \\
R \\
\end{array}$} & \multicolumn{4}{|c|}{ На всем участке поймы } & \multicolumn{4}{|c|}{ На первой площадке } \\
\hline & & $\hat{m}, \Gamma$ & $m, \Gamma$ & $\mathcal{E}, \Gamma$ & $\Delta, \%$ & $\hat{m}, \Gamma$ & $m, \Gamma$ & $\mathcal{E}, \Gamma$ & $\Delta, \%$ \\
\hline 1. Тысячелистник обыкновен. & 27 & 307 & 307 & $-0,03$ & $-0,01$ & 23 & 23 & $-0,09$ & $-0,40$ \\
\hline 2. Анис.обыкновенный & 28 & 309 & 309 & $-0,01$ & 0,00 & 27 & 27 & $-0,09$ & $-0,33$ \\
\hline 3. Вероника дубравная & 26 & 280 & 280 & $-0,12$ & $-0,04$ & 13 & 13 & 0,29 & 2,20 \\
\hline 4. Герань луговая & 29 & 368 & 368 & 0,02 & 0,00 & 39 & 39 & $-0,12$ & $-0,31$ \\
\hline 5. Одуванчик луговой & 25 & 237 & 237 & 0,07 & 0,03 & 0 & & $-0,08$ & \\
\hline 6. Подорожник ланцетный & 8 & 26 & 26 & 0,10 & $\mathbf{0 , 4 0}$ & 0 & & $-0,05$ & \\
\hline 7. Щучка дернистая & 21 & 115 & 115 & 0,03 & 0,03 & 0 & & $-0,08$ & \\
\hline 8. Тимофеевка луговая & 19 & 96 & 96 & $-0,01$ & $-0,01$ & 0 & & $-0,03$ & \\
\hline 9. Земляника лесная & 22 & 148 & 148 & $-0,04$ & $-0,03$ & 26 & 26 & 0,02 & 0,06 \\
\hline 10. Тростник обыкновенный & 30 & 416 & 416 & 0,03 & 0,01 & 21 & 21 & $-0,18$ & $-0,87$ \\
\hline 11. Манжетка & 16 & 61 & 61 & $-0,06$ & $-0,09$ & 31 & 31 & 0,09 & 0,28 \\
\hline 12. Мать-и-мачеха & 13 & 44 & 44 & 0,02 & 0,05 & 0 & & $-0,17$ & \\
\hline 13. Ежовник петушье просо & 15 & 57 & 57 & 0,03 & 0,05 & 0 & & $-0,07$ & \\
\hline 14. Василек луговой & 24 & 213 & 213 & 0,10 & 0,05 & 20 & 20 & 0,12 & 0,59 \\
\hline 15. Репей & 1 & 10 & 10 & 0,00 & 0,01 & 0 & & 0,00 & \\
\hline 16. Вейник обыкновенный & 23 & 182 & 182 & $-0,05$ & $-0,03$ & 0 & & 0,06 & \\
\hline 17. Полынь & 17 & 78 & 78 & $-0,06$ & $-0,08$ & 0 & & $-0,06$ & \\
\hline 18. Гулявник лекарственный & 9 & 26 & 26 & $-0,08$ & $-0,30$ & 0 & & 0,05 & \\
\hline 19. Пырей ползучий & 18 & 84 & 84 & 0,06 & 0,07 & 0 & & $-0,02$ & \\
\hline 20. Незабудка мелкоцветная & 5 & 22 & 22 & $-0,03$ & $-0,14$ & 0 & & $-0,01$ & \\
\hline 21. Донник лекарств. желтый & 4 & 19 & 19 & $-0,01$ & $-0,05$ & 0 & & $-0,01$ & \\
\hline 22. Гусиная лапка & 10 & 32 & 32 & 0,04 & 0,13 & 32 & 32 & $-0,07$ & $-0,22$ \\
\hline 23. Лютик ползучий & 2 & 13 & 13 & 0,00 & $-0,04$ & 13 & 13 & 0,00 & 0,01 \\
\hline 24. Белоус торчащий & 6 & 23 & 23 & $-0,01$ & $-0,04$ & 0 & & $-0,02$ & \\
\hline 25. Клоповник сорный & 1 & 10 & 10 & 0,00 & 0,01 & 0 & & 0,00 & \\
\hline 26. Цикорий & 20 & 102 & 102 & $-0,04$ & $-0,04$ & 0 & & $-0,01$ & \\
\hline 27. Лисохвост луговой & 4 & 19 & 19 & $-0,01$ & $-0,05$ & 0 & & $-0,01$ & \\
\hline 28. Плевел многолетний & 11 & 40 & 40 & $-0,03$ & $-0,07$ & 0 & & $-0,08$ & \\
\hline 29. Клевер красный & 3 & 16 & 16 & $-0,02$ & $-0,10$ & 0 & & 0,01 & \\
\hline 30. Костер безостый & 7 & 25 & 25 & $-0,06$ & $-0,23$ & 0 & & 0,01 & \\
\hline 31. Вьюнок полевой & 12 & 41 & 41 & 0,01 & 0,03 & 0 & & 0,12 & \\
\hline 32. Зверобой продырявлен. & 14 & 45 & 45 & $-0,05$ & $-0,11$ & 0 & & 0,15 & \\
\hline
\end{tabular}

Из данных таблицы 4 видно, что модель по параметрам из таблицы 3 получает максимальную относительную погрешность всего 0,40\%. 
Предлагаемое изобретение повышает функциональные возможности способа за счет более подробного по видам растений по сырой массе, причем без привязки к расстояниям по створам и вдоль реки, и даже без измерений высоты расположения пробной площадки над урезом воды.

\section{Литература}

1. Пат. 2556981 Российская Федерация, МПК А 01 G 23 / 00 (2006.01). Способ распределения видов луговой травы по массе свежесрезанной пробы / Мазуркин П.М., Михайлова С.И., Ямбаева О.С.; опубл. 20.07.2015. Бюл. № 20. http://www1.fips.ru/Archive/PAT/2015FULL/2015.07.20/DOC/RUNWC2/000/000/002/556/981/document.pdf

2. Mazurkin P.M. Identification of the wave patterns of behavior $/ / 14^{\text {th }}$ International multidisciplinary scientific geoconferenct \& SGEM2014. GeoConference jn NANO, BIO AND GREEN - TECHNOLOGIES FOR A SUSTAINABLE FUTURE. Conference proceedincs. Volume 1. Section Advances in Biotechnology. 17-26 June 2014. Albena, Bulgaria. P. 373-380.

3. Mazurkin P.M. Method of identification // $14^{\text {th }}$ International multidisciplinary scientific geoconferenct \& SGEM2014. GeoConference jn NANO, BIO AND GREEN - TECHNOLOGIES FOR A SUSTAINABLE FUTURE. Conference proceedincs. Volume 1. Section Advances in Biotechnology. 17-26 June 2014. Albena, Bulgaria. P. 427-434.

\section{METHOD DISTRIBUTION OF SPECIES OF MEADOW GRASS BY WEIGHT OF FRESHLY CUT SAMPLE}

Mazurkin PM, Mikhailova SI

VPO "Volga State University of Technology"

424000, Yoshkar-Ola, Russia, e-mail: kaf_po@mail.ru

Assessment of the species composition of the grass cover is carried out by statistical modelling by identifying the mathematical models of mass change of cut grass on the site and on a separate test site depending on the rank of species of grass and herbaceous plants. EFFECT: technology enables to increase the accuracy of accounting of the presence of species of grass and herbaceous plants, with simultaneous simplifying the evaluation process of species composition.

Keywords: grass, species, the sample, mass distribution, laws

\section{References}

1. Pat. Russian Federation 2556981, IPC A 01 G23 / 00 (2006.01). The method of distribution of species of meadow grass freshly cut sample by weight / Mazurkin PM, Mikhailova SI, Yambaeva OS; publ. 07/20/2015. Bull. Number 20.

http://www1.fips.ru/Archive/PAT/2015FULL/2015.07.20/DOC/RUNWC2/000/000/002/556/981/document.pdf

2. Mazurkin P.M. Identification of the wave patterns of behavior $/ / 14^{\text {th }}$ International multidisciplinary scientific geoconferenct \& SGEM2014. GeoConference jn NANO, BIO AND GREEN - TECHNOLOGIES FOR A SUSTAINABLE FUTURE. Conference proceedincs. V. 1. Sec. Advances in Biotechnology. 17-26 June 2014. Albena, Bulgaria. P. 373-380.

3. Mazurkin P.M. Method of identification // $14^{\text {th }}$ International multidisciplinary scientific geoconferenct \& SGEM2014. GeoConference jn NANO, BIO AND GREEN - TECHNOLOGIES FOR A SUSTAINABLE FUTURE. Conference proceedincs. Volume 1. Section Advances in Biotechnology. 17-26 June 2014. Albena, Bulgaria. P. 427-434. 